\title{
Aplicaciones de la biología molecular en la acuicultura
}

Eduardo Flores Coca1

1. Investigador del Centro de Investigación de Ecosistemas Acuáticos (CIDEA-UCA). Apto. 69. Managua, Nicaragua. E-mail: efcoca@ ns.uca.edu.ni

Recibido: agosto 2006 / Aceptado: octubre 2006

LA BIOTECNOLOGÍA ES UNA ESPECIALIDAD RECIENTE. A mediados de los años 80 se logró aplicar la técnica de la Reacción en Cadena de la Polimerasa como herramienta eficaz en la investigación científica. En la acuicultura, las herramientas moleculares se aplican en la investigación de nuevas especies útiles para el consumo, en investigaciones de determinación de relaciones filogenéticas de diferentes especies, para el mejoramiento genético de los organismos de cultivo como peces, camarones y algunos moluscos; además, en el diagnóstico y tratamiento de las enfermedades de los organismos acuáticos, pues también sirven como herramientas de diagnóstico eficaces y rápidas. En la actualidad, se utilizan sondas genéticas para hibridación in situ, para dot blot y diferentes tipos de PCR para detección de virus en organismos de cultivo. En el Centro de Investigación de Ecosistemas Acuáticos de la Universidad Centroamericana (UCA), se aplican técnicas moleculares para la detección de los virus WSSV, TSV, YHV e IHHNV y de la bacteria que produce NHP. Entre 2003 y 2004, se realizó un trabajo de monitoreo de los virus WSSV, TSV e IHHNV en los camarones silvestres del Estero Real y se determinó que la prevalencia en la época lluviosa fue de $1.97 \%$ para WSSV, $8.55 \%$ para TSV y $16.45 \%$ para IHHNV; en la época seca, la prevalencia fue de 15.33 \%para WSSV, $13.33 \%$ para TSV y $0.67 \%$ para IHHNV. La prevalencia total en todo el año de WSSV es de $8.67 \%$, 11\% para TSV y 8.67\% para IHHNV. Finalmente, el total de prevalencia en todo el año, sumando los tres virus, es de $28.33 \%$.

Palabras clave: acuicultura-investigación / mejoramiento de las especiesinvestigación / polimerización

\section{Introducción}

La Biotecnología, entendida como la aplicación en procesos industriales de organismos vivos o parte de ellos para la producción de bienes, es antigua en términos históricos. Pero como especialidad de las Ciencias Biológicas, sus aplicaciones son más recientes.

Los hallazgos científicos de la segunda mitad del siglo XX dieron el empuje necesario para el desarrollo de la biotecnología como especialidad científica. Como punto de partida, se menciona la definición de la estructura de doble hélice y replicación del ADN 
propuesta por James Watson y Francis Crick en 1953 (Stryer, 1995:80); la composición del código genético propuesto por Crick, Brenner, Nirenberg y otros entre 1961 y 1965 (Stryer, 1995: 100-111); la clonación del ADN en 1973 (Lewin, 1994:51), anticuerpos monoclonales en 1975, secuenciación del ADN y clonación de genes humanos entre 1975 y 1977; aplicación de la Reacción en Cadena de la Polimerasa en 1984; y la clonación de la oveja Dolly en 1997.

De todos esos hallazgos, el que más aceleró los avances científicos fue la aplicación de la Reacción en Cadena de la Polimerasa (PCR), herramienta ideada y aplicada por Kary Mullins a mediados de los años 80, que consiste en multiplicar exponencialmente secuencias específicas de ADN de manera mecánica a partir de un par de secuencias iniciadoras o primers, de una enzima polimerasa termo resistente, sintetizada a partir de una bacteria llamada Thermus acuaticus; y de una mezcla de nucleótidos y mezclas tampón para producir la reacción.

\section{Aplicaciones diagnósticas en la acuicultura}

Todas las áreas de la vida humana han sido influidas por esta corriente de avances científicos y la acuicultura es una actividad económica que los ha aprovechado intensamente. Muchas especies adecuadas para consumo humano han sido determinadas a partir de la aplicación de métodos moleculares que contribuyen a determinar los aportes nutricionales de estas especies a la alimentación humana. Recientemente, se aplicaron las técnicas de PCR-RFLP en camarones brasileños para determinar si eran aprovechables comercialmente (Gusmao y Solé-Cava, 2003).

Para la conservación y explotación racional de los recursos marinos, es necesario determinar claramente las especies endémicas de cada región. La aplicación de estudios de relaciones filogenéticas de diferentes especies ha determinado el origen y distribución de una gran cantidad de especies marinas comercialmente explotables, como se refleja en la Ilustración 1, donde se determina las relaciones filogenéticas de algunas especies de carpas en Europa y América del Norte. (Gonzáles, J., 2002). 

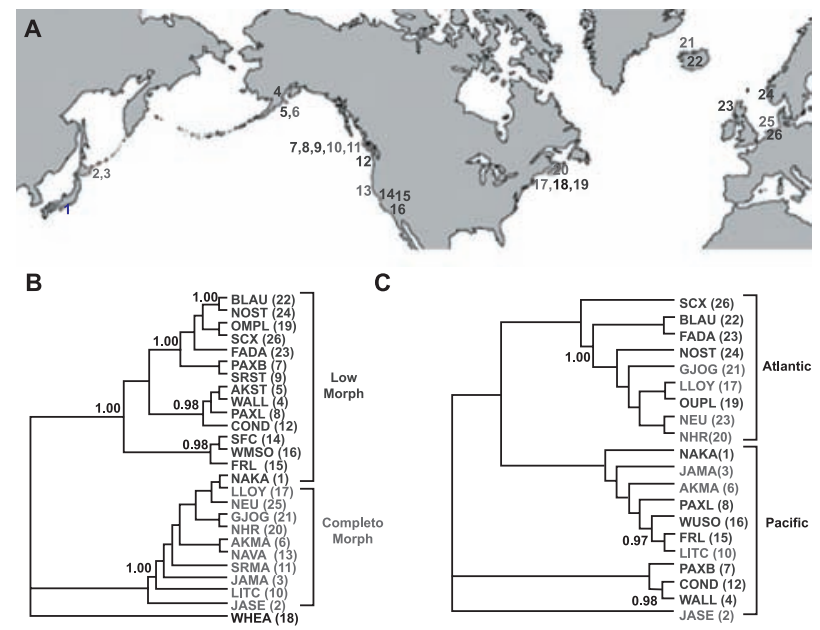

C

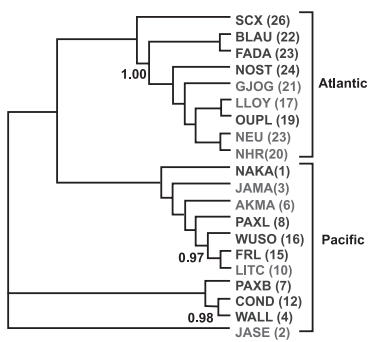

Ilustración 1. Relaciones filogenéticas de algunas especies de carpas en Europa y América del Norte.

Las herramientas moleculares se han aplicado en el mejoramiento genético en diferentes organismos acuáticos. Algunos laboratorios productores de larvas de camarón han mejorado genéticamente algunas especies para que soporten las enfermedades, principalmente virales, que les afectan. Esto se consigue aplicando marcadores moleculares para la activación de genes específicos que permiten al organismo superar las infecciones virales, como la producida por el virus del Síndrome de la Mancha Blanca (WSSV) (Curie, D. J., 1994; Hasson, K., 2003).

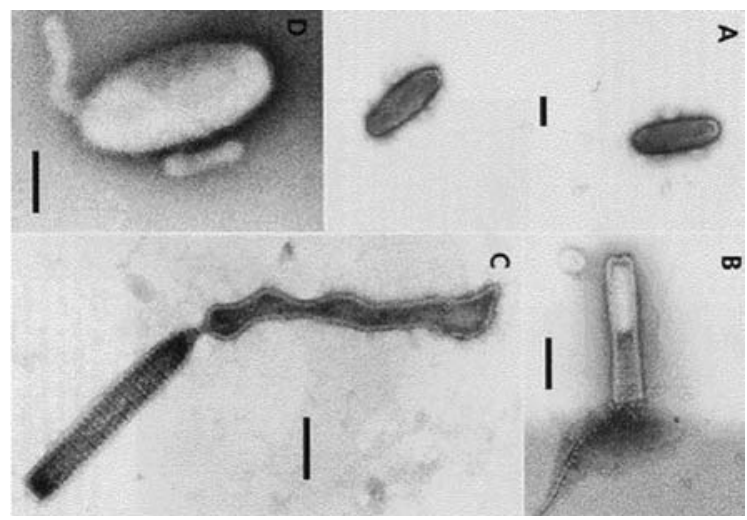

Ilustración 2. Fotografía donde se muestra el virus del Síndrome de la Mancha Blanca (WSSV) en sus diferentes etapas de infección.

Una de las principales aplicaciones que se da a las herramientas moleculares en acuicultura es en el área de diagnóstico y tratamiento de enfermedades que atacan a los especimenes de cultivo. Esta área es vital en la industria porque la aparición de brotes de enfermedades 
produce enormes pérdidas que merman la producción. Los principales agentes patógenos presentes en la industria son los hongos, bacterias y, principalmente, los virus, sobre los que, en muchos casos, se carece de información y tratamientos (Chu-Fang Lo, 1996; Lightner, D. V. y Pantoja, C. R., 2001).

Entre las técnicas moleculares más aplicadas en la acuicultura se encuentran la Reacción en Cadena de la Polimerasa (PCR) o amplificación exponencial de secuencias de ADN específicas; Dot Blot, que es la utilización de sondas genéticas específicas que se complementan a sus secuencias homólogas de ADN fijado en membranas, principalmente nitrocelulosa; e Hibridación in situ, que es también el uso de sondas genéticas, pero en este caso fijadas en el tejido infectado propiamente dicho, tratado previamente con técnicas histológicas (Lightner, D. V., 1996).

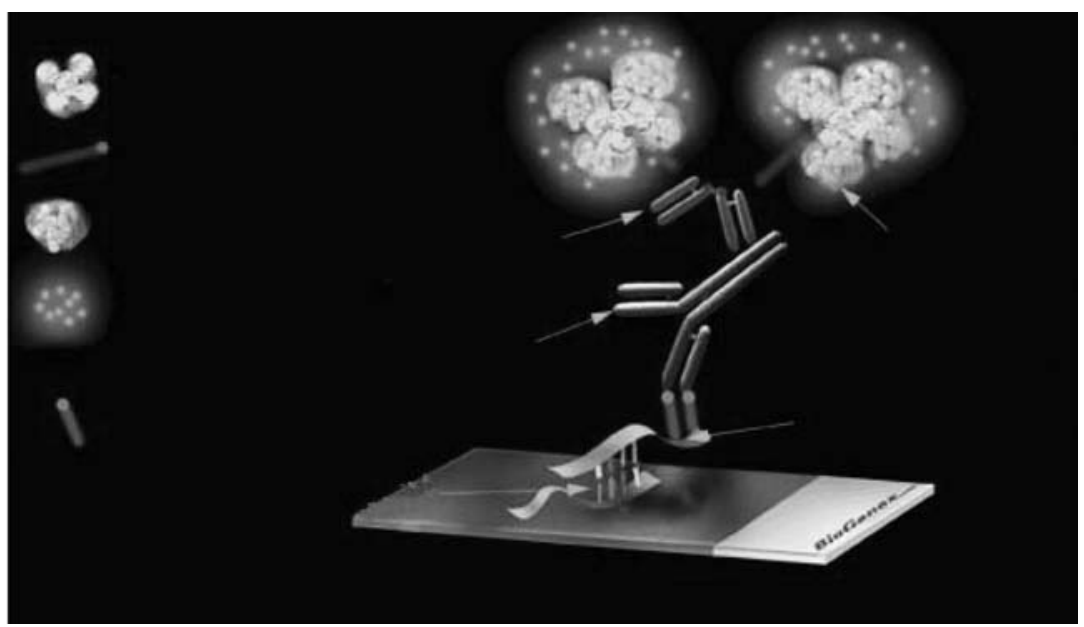

Ilustración 3. La Hibridación in situ utiliza sondas genéticas marcadas con anticuerpos que, al ser revelados, permiten observar los antígenos marcados con Dioxigenina.
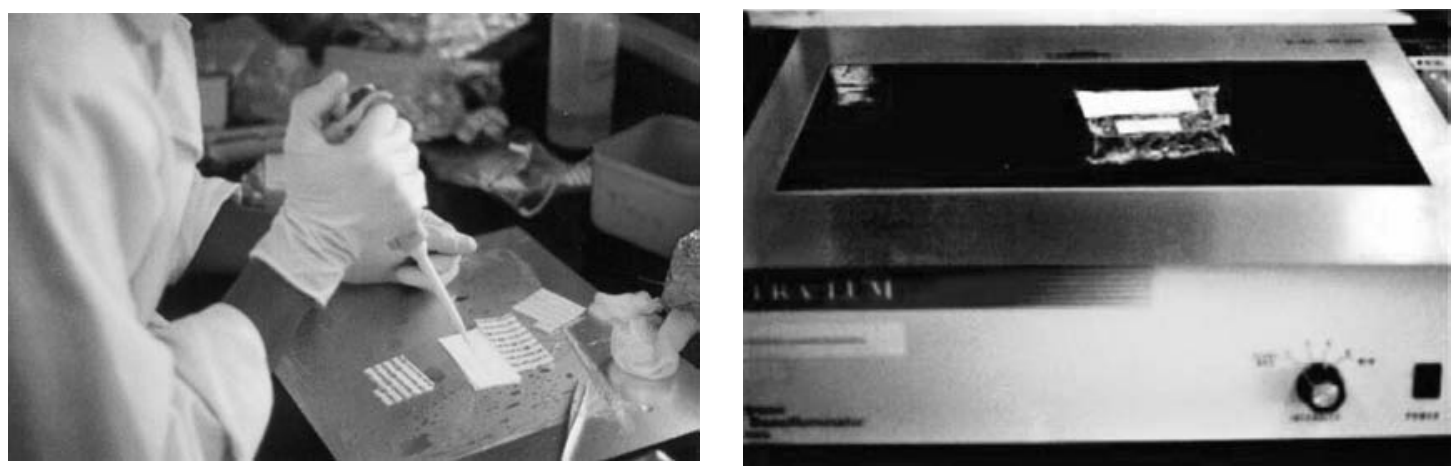

Ilustración 4. En la técnica Dot Blot, el ADN molde se fija en una membrana, generalmente de nitrocelulosa, en la que se aplica la sonda genética y los anticuerpos marcados con dioxigenina. 
En la camaronicultura, estas herramientas se usan ampliamente para el diagnóstico de patógenos bacteriológicos y virales: bacterias del tipo ricketsia y virus como el del Síndrome de la Macha Blanca, Síndrome de Taura (TSV), Cabeza Amarilla (YHV) y el virus de la Necrosis Muscular Infecciosa o Mionecrosis IMN.

La diferencia en la aplicación de estas técnicas en las labores de diagnóstico está en la sensibilidad y el tiempo para emitir resultados. Está comprobado que la aplicación del PCR para el diagnóstico de patógenos garantiza una mayor sensibilidad en la detección, porque se identifican cantidades más pequeñas de partículas infecciosas por unidad de análisis, en comparación con las anteriores técnicas de diagnóstico. Está debidamente comprobado que el PCR tiene la ventaja que se puede tener resultados en menos tiempo que con las otras técnicas descritas.

La aplicación del diagnóstico de patógenos a tiempo ha disminuido drásticamente las pérdidas por mortalidades y ha aumentado la producción de organismos de cultivo.

En la actualidad, en el Centro de Investigación de Ecosistemas Acuáticos de la UCA, se aplica el diagnóstico molecular de los Virus del Síndrome de la Macha Blanca (WSSV), Virus del Síndrome de Taura (TSV), Virus de la Necrosis Hematopoyética e Hipodermal Infecciosa (IHHNV), Virus de la Cabeza Amarilla (YHV) y de la bacteria tipo ricketsia que produce la Hepatopancratitis Necrotizante (NHP). Todos estos análisis han sido debidamente validados, confirmando la repetibilidad, exactitud y robustez de los resultados, además de la pureza de los reactivos que se utilizan, con lo que se logra que estos análisis sean acreditados con la Norma Técnica Nicaragüense, homóloga de la Norma Internacional ISO 17025. Con esto, se provee a los acuicultores nicaragüenses, de diagnósticos moleculares confiables y de laboratorios debidamente acreditados.

\section{Herramientas moleculares en la investigación acuícola}

La investigación científica es determinante para el desarrollo de la acuicultura y la aplicación de herramientas moleculares está ampliamente difundida.

Los temas de investigación son muy amplios. Incluyen genética de poblaciones, mejoramiento genético, modificaciones genéticas de organismos para garantizar resistencia a enfermedades y patógenos específicos, y producción de vacunas, medicamentos o métodos de diagnóstico rápidos, sensibles y sencillos. 


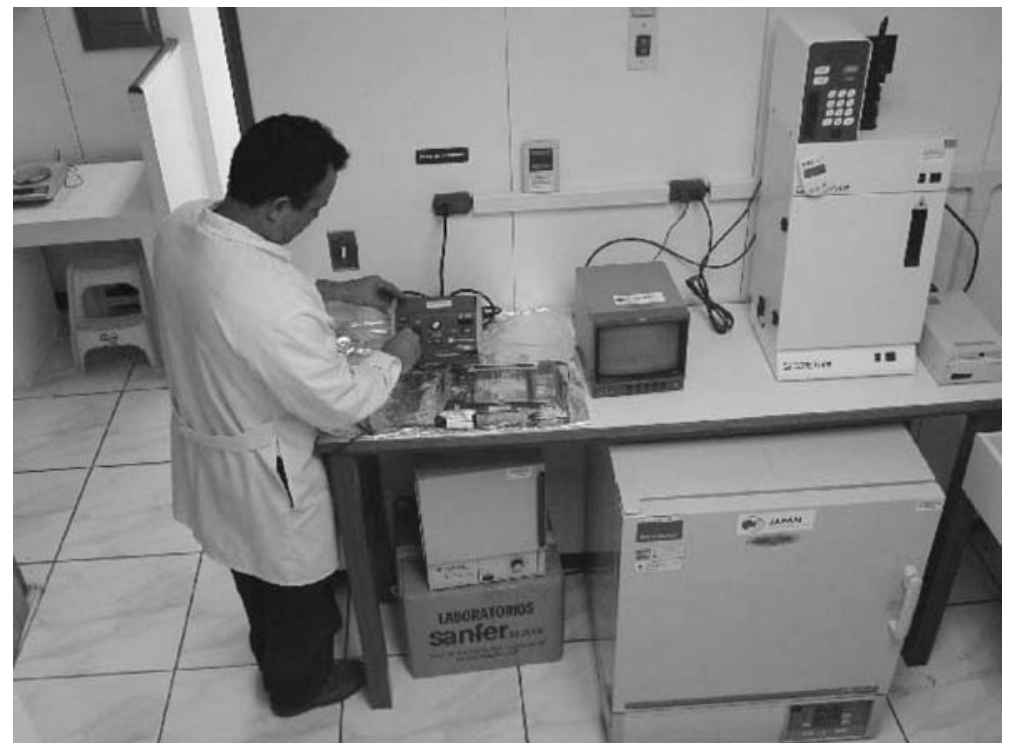

Ilustración 5. En los laboratorios del CIDEA-UCA, se aplican técnicas moleculares para la detección rápida de virus que afectan a la industria del camarón en Nicaragua.

En Nicaragua, el estado no tiene políticas ni estrategias para desarrollar la acuicultura. Por lo tanto, tampoco desarrolla los esfuerzos necesarios de investigación. Por lo tanto, estos esfuerzos se realizan por particulares, sean instituciones o empresas. La consecuencia es que hay muy pocos investigadores y muy pocas investigaciones.

En los años 2003 y 2004, se hizo una investigación cuyos resultados han ayudado a la industria acuícola a prevenir las principales enfermedades que atacan al camarón. Los resultados de esa investigación se presentan a continuación.

El tema de la investigación es "Monitoreo de los virus WSSV, TSV e IHHNV en camarones pendidos silvestres de Puerto Morazán en época seca y época lluviosa de los años 2003 y 2004”. El trabajo se llevó a cabo entre las temporadas secas y lluviosas de los años 2003 y 2004, con camarones silvestres que se distribuyen en la zona camaronera de Puerto Morazán, ubicada en el centro del Estero Real, la principal zona de producción camaronera de Nicaragua y Honduras.

Los sistemas estuarinos como el Estro Real son importantes para gran número de especies marinas, entre ellas los camarones Litopenaeus que son el objeto de estudio, y las especies de cultivo en Nicaragua. Después de que los camarones adultos copulan y desovan, arrojan los huevos en mar abierto; cuando eclosionan, pasan unas tres semanas en aguas oceánicas; para continuar su desarrollo, las larvas alcanzan los sistemas estuarinos que sirven como áreas de crianza para muchas especies marinas, ya que las raíces de los árboles en el manglar les protegen y proporcionan abundante alimento. Los camarones permanecen dentro o cerca de los sistemas estuarinos hasta alcanzar la talla de 4 a $10 \mathrm{~cm}$ (Martínez Córdova, 1999). 


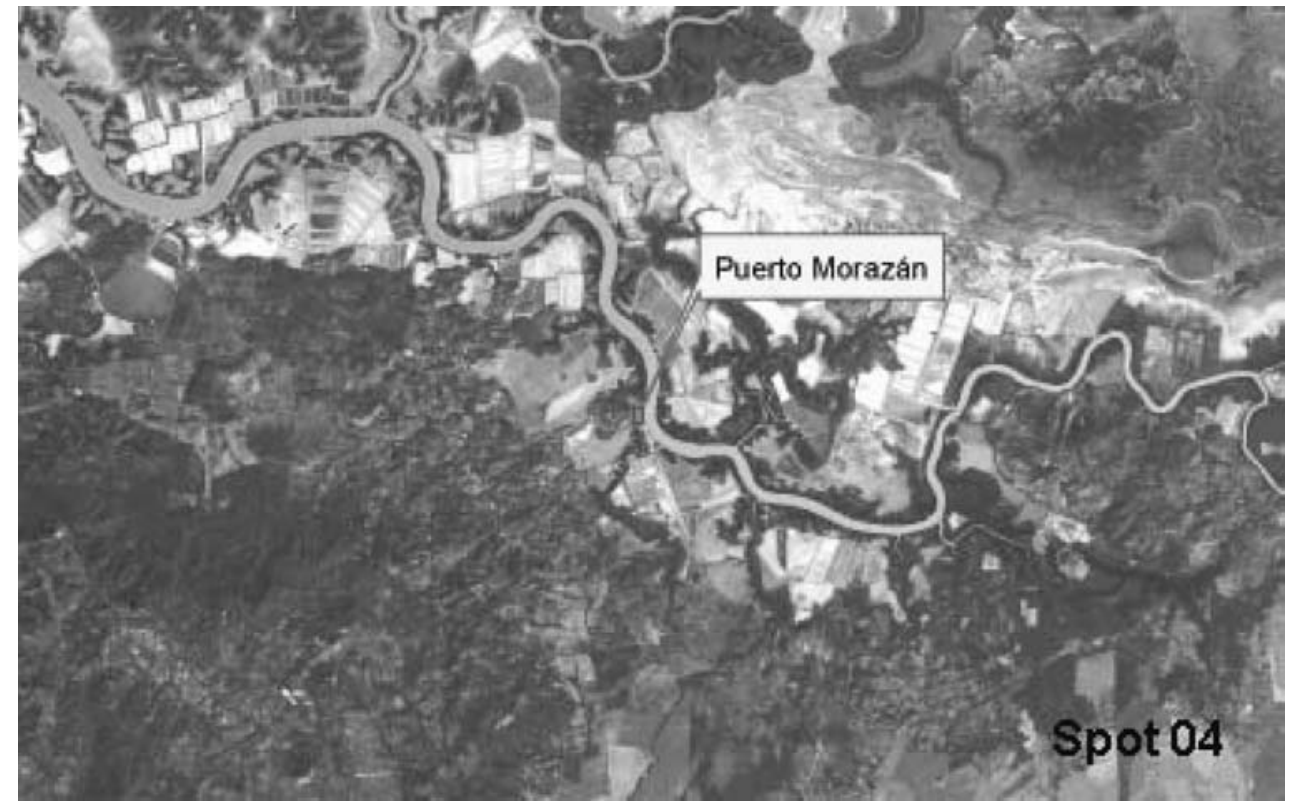

Ilustración 6. Ubicación del punto de muestreo en Puerto Morazán, Estero Real. (SIG-CIDEA, 2005).

Se monitorearon tres virus: el Virus del Síndrome de Mancha Blanca (WSSV), que es un baculovirus de ADN de cadena doble, clasificado como Nimaviridae; el Virus del Síndrome de Taura, que es un virus icosahedrico de ARN de una sola hebra lineal positiva, clasificado como Picornaviridae; y el Virus de la Necrosis Hematopoyética e Hipodermal Infecciosa, que es un virus icosahedrico de $\mathrm{ADN}$ de una cadena lineal, clasificado como Parvoviridae.

Para este estudio se recolectaron 150 muestras en cada una de las estaciones climáticas y se calculó la prevalencia de cada uno de los tres virus estudiados en cada muestra y estación climática. La prevalencia se calcula de esta manera: $\mathrm{P}=\left(\mathrm{N}^{0}\right.$ de individuos afectados $/ \mathrm{N}^{0}$ total de individuos)*100 (Lightner, 1996).

Durante la toma de muestras, se utilizaron artes de pesca como atarrayas, chayos, tinas plásticas, coladores y panas. La colecta se hizo en diferentes puntos de la ribera del río en el poblado de Puerto Morazán. Las muestras vivas se identificaron y se fijaron en etanol 95\% en una proporción de 1:10 de tejido contra fijador, se rotularon debidamente y se enviaron al laboratorio.

Para los análisis de los virus se usaron los kit de reactivos siguientes:

- Para el virus WSSV, se usó el kit IQ-2000 (Manual, 2002).

- Para el Virus TSV, se usó el kit IQ-2000 (Manual, 2003).

- Para el Virus IHHNV, se usó el kit IQ-2000 (Manual, 2002).

Los resultados para cada prueba, son los siguientes: 


\section{Para WSSV}

Los resultados positivos y negativo se aprecian en la Ilustración 7:
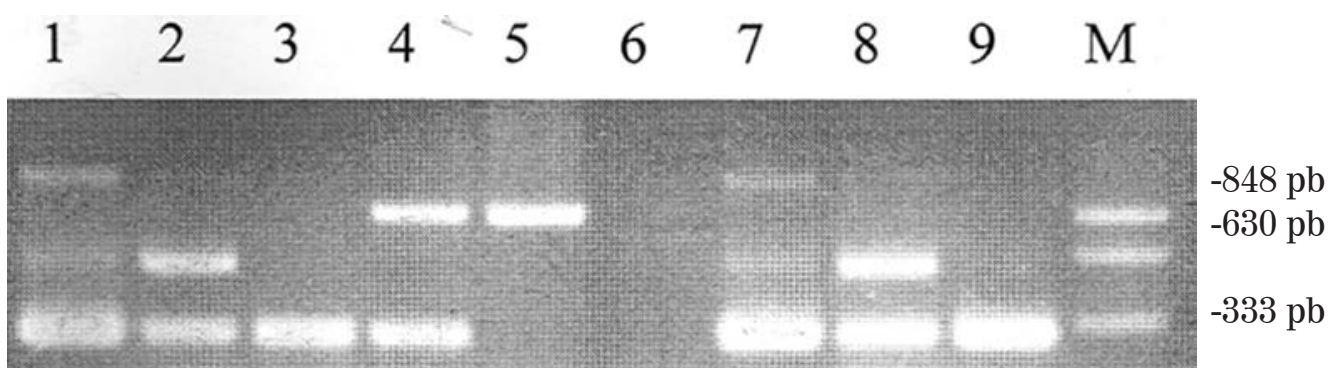

Ilustración 7. Foto del gel de agarosa $2 \%$ con todos los resultados posibles del análisis del Virus de Mancha Blanca.

Simbología: Línea 1 Positivo Severo WSSV; Línea 2 Positivo Medio WSSV; Línea 3 Positivo Leve WSSV; Línea 4 Positivo Muy Leve

Línea 5 Negativo; Línea 6 ddH $_{2}$; Línea 7 Std. 103; Línea 8 Std. 10²; Línea 9 Std. 10; M: Marcador

Las muestras positivas presentan bandas de $\mathrm{ADN}$ de $296 \mathrm{pb}$ únicamente, o bien $296 \mathrm{pb}$ y $550 \mathrm{pb}$; también pueden presentar bandas de 296 pb, $550 \mathrm{pb}$ y $910 \mathrm{pb}$, como se aprecia en las líneas 1, 2 y 3 de la Ilustración 7.

Las muestras negativas presentan una banda de ADN de $848 \mathrm{pb}$, correspondiente al ADN del genoma del camarón, como se aprecia en la línea 5 de la llustración 7.

\section{Para TSV}

Los resultados positivos y negativo se aprecian en la Ilustración 8:

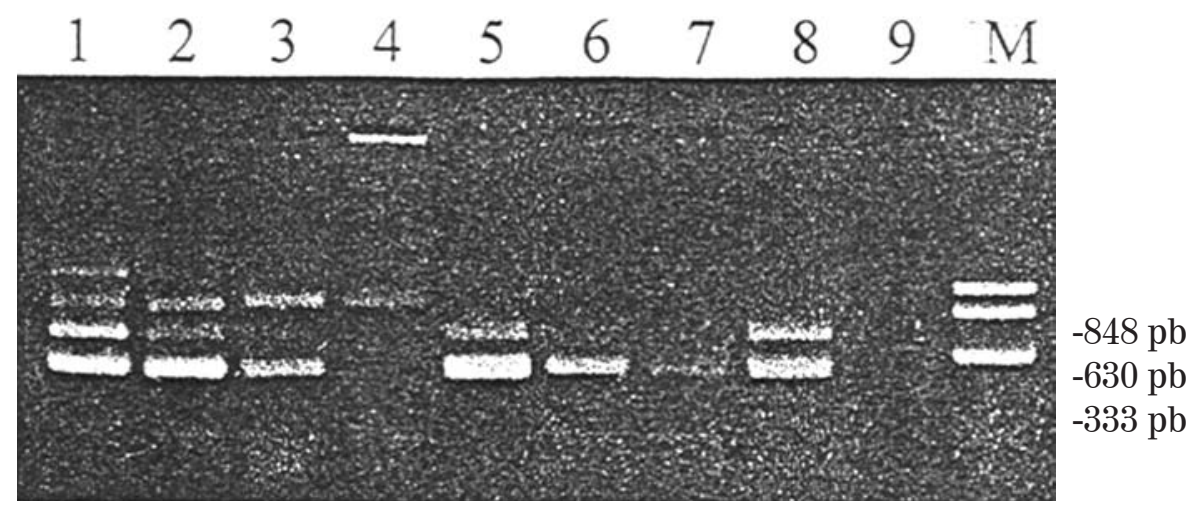

Ilustración 8. Foto del gel de agarosa $2 \%$ con todos los resultados posibles del análisis del Virus Taura. 
Simbología: Línea 1 positivo IHHNV; Línea 2 pos medio IHHNV; Línea 3 pos leve IHHNV; Línea 4 negativo; Línea 5 ddH $_{2} \mathrm{O}$; Línea 6 Std 103; Línea 7 Std 10²; Línea 8 Std 10¹; M: Marcador Las muestras con bandas de $\mathrm{ADN}$ de 284 pb y 476 pb son positivas; las muestras con bandas de $\mathrm{ADN}$ de $284 \mathrm{pb}$ son positivas. Como se aprecia en las líneas 1, 2 y 3 de la Ilustración 8, y las muestras con bandas de ADN de $680 \mathrm{pb}$, son negativas, correspondiente al ADN del genoma del camarón como se aprecia en la línea 4 de la Ilustración 8.

\section{Para IHHNV}

Los resultados positivos y negativo se aprecian en la Ilustración 9:

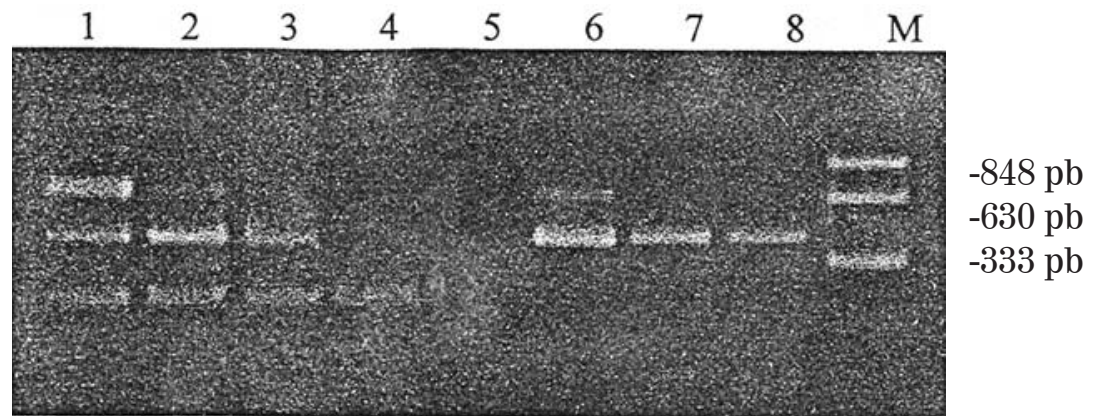

Ilustración 9. Foto del gel de agarosa 2\% con todos los resultados posibles del análisis de IHHNV.

Simbologìa: Línea 1 Severo TSV; Línea 2 Medio TSV; Línea 3 Leve TSV; Línea 4 Negativo Línea 5 Std 103; Línea 6 Std 10²; Línea 7 Std 10¹ Línea 8 control +; Línea 9 ddH $_{2} 0$ M: Marcador

Las muestras positivas presentan bandas de 438 pb o bandas de 438 pb y 644 pb. Como se aprecia en las líneas 1, 2 y 3 de la Ilustración 9, las muestras negativas presentan bandas de 243 pb. Correspondiente al ADN del genoma del camarón como se aprecia en la línea 4 de la Ilustración 9.

\section{Resultados}

En la época de lluvia, las muestras positivas para WSSV fueron 3 para una prevalencia de 1.97\%; las muestras positivas de TSV fueron 13 para una prevalencia de 8.55\%; y las muestras positivas de IHHNV fueron 25 para una prevalencia de $16.45 \%$ (Cuadro 1 ).

Cuadro 1. Número de muestras positivas y prevalencia de los tres virus en la época lluviosa.

\begin{tabular}{|c|c|c|}
\hline Virus & Positivos & Prevalencia \\
\hline WSSV & 3 & 1.97 \\
\hline TSV & 13 & 8.55 \\
\hline IHHNV & 25 & 16.45 \\
\hline
\end{tabular}


La prevalencia total de los tres virus en la época lluviosa fue de $27.33 \%$.

\section{Prevalencia en época lluviosa}

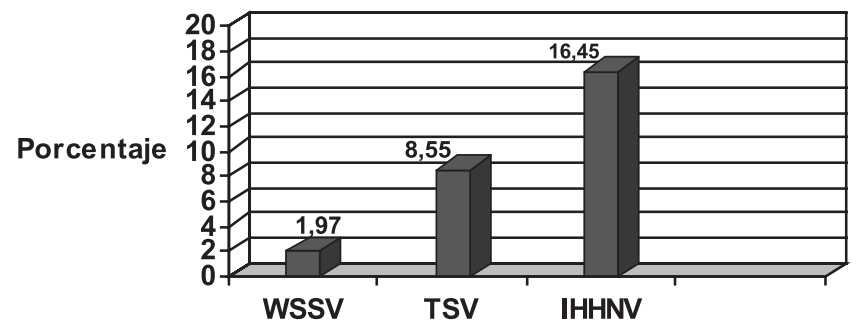

Ilustración 10. Prevalencia en época lluviosa.

En la época seca las muestras positivas para WSSV fueron 23 para una prevalencia de 15.33 $\%$; las muestras positivas de TSV fueron 20 para una prevalencia de 13.33\%; y las muestras positivas de IHHNV fue 1 para una prevalencia de $0.67 \%$ (Cuadro 2).

Cuadro 2. Número de muestras positivas y prevalencia de los tres virus en la época seca.

\begin{tabular}{|c|c|c|}
\hline Virus & Positivos & Prevalencia \\
\hline WSSV & 23 & 15.33 \\
\hline TSV & 20 & 13.33 \\
\hline IHHNV & 1 & 0.67 \\
\hline
\end{tabular}

La prevalencia total de los tres virus en la época seca fue de $29.33 \%$

\section{Prevalencia en época seca}

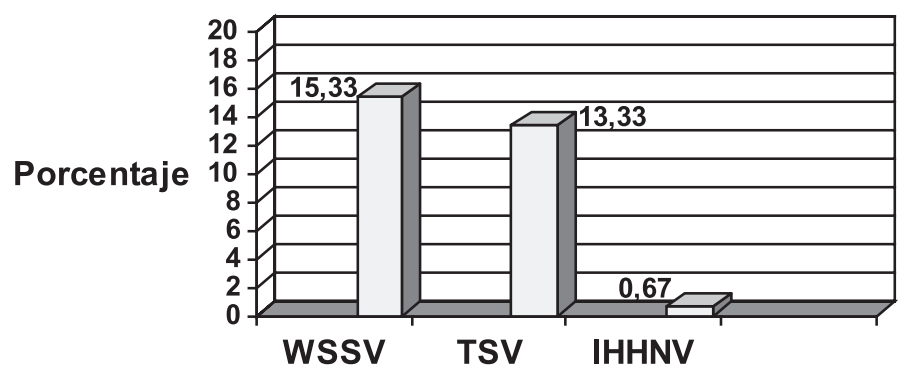

Ilustración 11. Prevalencia en época seca. 
El total de muestras positivas para WSSV en ambos períodos fue de 26 para una prevalencia de 8.67\%; el total de muestras positivas para TSV en ambos períodos fue de 33 para una prevalencia de $11 \%$; y el total de muestras positivas para IHHNV en ambos períodos fue de 26 para una prevalencia de $8.67 \%$.

La prevalencia total de los tres virus en los camarones silvestres en ambos períodos estudiados fue de $28.33 \%$, resultando un total de 85 muestras infectadas con alguno de los tres virus de las 300 recolectadas.

\section{Prevalencia en ambas épocas del año}
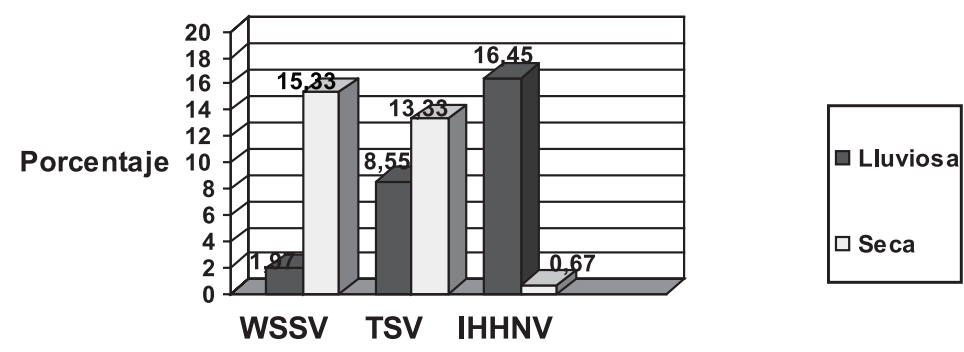

Prevalencia total

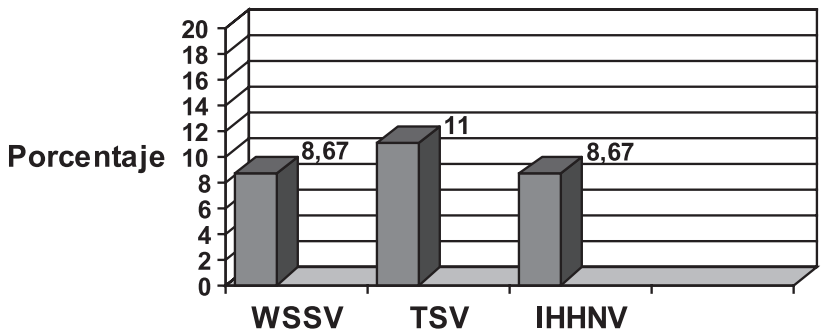

Ilustración 12. Prevalencia en ambas épocas del año y prevalencia total.

\section{Discusión}

Los resultados demuestran que los tres virus estudiados, -Virus del Síndrome de la Mancha Blanca, Virus del Síndrome de Taura y Virus de la Necrosis Hematopoyética e Hipodermal Infecciosa-, están presentes en los camarones pendidos silvestres que se mueven en las aguas del Estero Real. Esto es una amenaza permanente de brotes epidémicos de cualquiera de esas enfermedades en las granjas camaroneras asentadas en ese cuerpo de agua, teniendo en cuenta que hay un $28.33 \%$ de prevalencia de los tres virus en todo el año.

Las estaciones lluviosa y seca manifestaron comportamientos diferenciados en la prevalencia de los virus en los camarones pendidos silvestres. El virus de IHHNV aparece de manera más frecuente en la época lluviosa y, en segundo lugar, el virus TSV. En cambio, en la época seca, 
se manifiesta de manera más frecuente el virus WSSV seguido del virus TSV. Esto podría explicar la presencia de brotes en las granjas en algunas épocas del año. Las causas de este comportamiento no se investigaron en este trabajo, por lo que es necesario encontrar la explicación en trabajos futuros.

El virus TSV es el que más prevalencia presentó en promedio en ambas épocas: su prevalencia fue mayor del 10\%, lo que puede explicarse porque este virus tiene más tiempo de haberse asentado en el país. Esto explicaría por qué en las granjas camaroneras se dan brotes epidémicos durante todo el año, si no se aplican las medidas de bioseguridad adecuadas.

Las autoridades reguladoras de la actividad acuícola deben tener en cuenta las regulaciones fitosanitarias necesarias para evitar la aparición de brotes epidémicos en las granjas camaroneras, producto de malas prácticas de manejo. Estas medidas deberán incluir los análisis de laboratorio de manera obligatoria de estos tres virus (actualmente se exige para WSSV y TSV) a todas las postlarvas que se vayan a sembrar, tanto silvestres como de laboratorio, porque alguno de estos virus no presentan altas mortalidades necesariamente y, por lo tanto, las postlarvas pueden ser portadoras de dichos patógenos. Esto es necesario porque la prevalencia total de los tres virus durante todo el año, que es de $28.33 \%$, es alta para organismos silvestres y demuestra que hay un gran potencial para que se produzcan brotes epidémicos.

Es necesario realizar estudios similares en todo el cuerpo de agua del Estero Real durante varias temporadas consecutivas para tener más clara la situación de los organismos silvestres. Asimismo, elaborar un plan de manejo adecuado para ese cuerpo de agua con el fin de evitar que la fauna marina de crustáceos disminuya drásticamente a consecuencia de brotes de enfermedades virales y asociadas.

\section{Referencias bibliográficas}

-ADPESCA (2005). Anuario Pesquero y Acuícola pesquero de Nicaragua, Managua, 2:7. -BOWER, S. M. (1996). Sinopsis of Infectius Diseases and Parasites of Commercially Exploited Shellfish: Infectius Hypodermal and Hematopoietic Necrosis Virus of Penaeid Shrimp. Disponible en Internet: www.sci.pac.dfo_mpo.gc.ca

-CHU-FANG LO et al., (1996). PCR Monitoring of cultura shrimp for White Spot Syndrome Virus, infection grow out pounds, DAO, 15:23.

-CURIE, D. J. (1994). Ordenamiento de la Camaronicultura Estero Real, Nicaragua, Proyecto Fortalecimiento de la Acuicultura, Pradepesca, Informe anual.

-FARMING INTELLIGENE TECHNOLOGY CORPORATION (2002).Detection and Prevention System for White Spot Syndrome Virus (WSSV), Manual. Disponible en Internet:

www.iq2000kit.com

-FARMING INTELLIGENE TECHNOLOGY CORPORATION, (2004). Detection System for Infectius Hypodermal and Hematopoietic Necrosis Virus (IHHNV), Manual. Disponible en Internet: www.iq2000kit.com

-FARMING INTELLIGENE TECHNOLOGY CORPORATION, (2004). Detection and Prevention System for Taura Syndrome Virus (TSV), Manual. Disponible en Internet: 
www.iq2000kit.com

-FIGUEROA, Y. B. y FLORES COCA, E. (2002). Distribución del Virus del Síndrome de la Mancha Blanca en las costas y esteros de la República de Panamá, 17:25.

-GOBIERNO DE NICARAGUA (2002). Norma Técnica Sanitaria para la Importación y Movilización de Organismos Acuáticos en el Territorio Nacional, Diario Oficial, Gaceta $\mathrm{N}^{\circ} 99$ del 29-05-2002.

-GONZÁLEZ, J. (2002). El Virus de la Mancha Blanca: un ejemplo de la vulnerabilidad de la camaronicultura en la región de América Latina y el Caribe. Disponible en Internet: www.fao.org

-GUSMAO, J. y SOLÉ-CAVA, A. M. (2003). "Sistema de diagnóstico molecular para la identificación de especies comerciales de camarones marinos brasileños" Panorama Acuícola, Enero/Febrero.10:11.

-HASSON, K. (2003). Patógenos de camarones pendidos cultivados con énfasis en problemas actuales de enfermedades, Simposio Internacional de Camarón de Cultivo, Nicaragua.

-LEWIN, B. (1994). Genes IV, Ed. Reverté, SA., España.

-LIGHTNER, D. V. (1996). A handbook of pathology and diagnostic procedures for diseases of penaeid shrimp. World Aquaculture Society.

-LIGHTNER, D. V. y CHEN, S. N. (2002). Necrosis Hipodérmica y Hematopoyética Infecciosa. Disponible en Internet: www.oie.int

-LIGHTNER, D. V. et. al., Proceedings of the Taura Syndrome Virus Workshop: executive summary, Submites reports and transcribed notes.

-LIGHTNER, D. V. y PANTOJA, C. R. (2001). Bioseguridad en el cultivo de camarones. Métodos para mejorar la Camaronicultura en Centroamérica, Ed. UCA

-MARTÍNEZ CÓRDOVA, L. R. (1999). Cultivos de Camarones Pendidos: Principios y Prácticas, AGT Editor, SA. 8:15.

-Outbreak of shrimp viral disease in Central America: Situation Report. Disponible en Internet: www.aphis.usda.gov

-Sistema de Información Geográfica, Centro de Investigación de Ecosistemas Acuáticos, (2005).

-STRYER, L. (1995). Bioquímica, Ed. Reverté, SA. España, 80 :111.

-Virus del Síndrome de Taura. Disponible en Internet: www.aapqis.org

-White Spot Syndrome Baculovirus Complex of Penaeid Shrimp. Disponible en Internet: www.pac.dfopo.gc.ca 